\title{
Effect of Aerogel Particle Concentration on Mechanical Behavior of Impregnated RTV 655 Compound Material for Aerospace Applications
}

\author{
Firouzeh Sabri, ${ }^{1}$ Jeffrey G. Marchetta, ${ }^{2}$ K. M. Rifat Faysal, ${ }^{1}$ Andrew Brock, ${ }^{1}$ and Esra Roan ${ }^{2}$ \\ ${ }^{1}$ Department of Physics, University of Memphis, Memphis, TN 38152, USA \\ ${ }^{2}$ Department of Mechanical Engineering, University of Memphis, Memphis, TN 38152, USA
}

Correspondence should be addressed to Firouzeh Sabri; fsabri@memphis.edu

Received 5 March 2014; Revised 27 July 2014; Accepted 29 July 2014; Published 15 October 2014

Academic Editor: Luigi Nicolais

Copyright (C) 2014 Firouzeh Sabri et al. This is an open access article distributed under the Creative Commons Attribution License, which permits unrestricted use, distribution, and reproduction in any medium, provided the original work is properly cited.

Aerogels are a unique class of materials with superior thermal and mechanical properties particularly suitable for insulating and cryogenic storage applications. It is possible to overcome geometrical restrictions imposed by the rigidity of monolithic polyurea cross-linked silica aerogels by encapsulating micrometer-sized particles in a chemically resistant thermally insulating elastomeric "sleeve." The ultimate limiting factor for the compound material's performance is the effect of aerogel particles on the mechanical behavior of the compound material which needs to be fully characterized. The effect of size and concentration of aerogel microparticles on the tensile behavior of aerogel impregnated RTV655 samples was explored both at room temperature and at $77 \mathrm{~K}$. Aerogel microparticles were created using a step-pulse pulverizing technique resulting in particle diameters between $425 \mu \mathrm{m}$ and $90 \mu \mathrm{m}$ and subsequently embedded in an RTV 655 elastomeric matrix. Aerogel particle concentrations of 25, 50, and $75 \mathrm{wt} \%$ were subjected to tensile tests and behavior of the compound material was investigated. Room temperature and cryogenic temperature studies revealed a compound material with rupture load values dependent on (1) microparticle size and (2) microparticle concentration. Results presented show how the stress elongation behavior depends on each parameter.

\section{Introduction}

Long-distance space travel is currently limited due to availability of fuel for such missions. Current technology relies on storage of cryogenic fuel in metallic containers, not practical for large quantities necessary for long-term travel. Polymeric materials are a highly adaptable group of materials with a broad range of applications that span the biomedical field to the space industry [1-3]. The versatility of polymer synthesis and processing has provided an excellent platform for the development of custom-designed, application-specific polymers with unique properties. Most polymers however suffer from low mechanical stiffness [4-6] and have limited load bearing capabilities which in turn limits their use but has been addressed in some studies by incorporating microand nanosized particles into the polymeric matrix $[4,7-10]$. The final mechanical strength of the impregnated polymers strongly depends on particle parameters such as particle size, geometry, concentration [11-14], and stress transfer between the encapsulated particles and the polymer matrix [15]. In general, if the applied stress is transferred effectively from the matrix to the particles the result will be a stronger material [16-20]. Since the introduction of micronanoparticles into a polymer matrix can have a variety of effects on the overall behavior of the material, each particle-polymer combination must be independently and thoroughly characterized and the limits of the material tested under different environmental conditions.

Aerogels are a relatively new class of materials with unique material properties particularly suitable for the aerospace industry. Aerogels are currently the best known solid thermal insulators and have been explored extensively for insulation applications both in the monolith form and in particle and bead geometries [21-23]. Low concentration $(<15 \%)$ native aerogel-impregnated polymers have been investigated previously for thermal insulation applications $[24,25]$ and demonstrated great promise for applications such as cryogenic tank systems and insulation on the Mars 
exploration rovers [26]. Among the various types of aerogels, polyurea cross-linked silica aerogel (PCSA) is an attractive candidate for this study due to its relatively lower production cost, compatibility with green technology, and most importantly enhanced mechanical strength accomplished by covalent cross-linking of the polymer chains while retaining a high degree of porosity $[27,28]$. The PCSA is also hydrophobic in comparison to the native silica aerogels making this type of aerogel most suitable for applications where there is a possibility for aerogel components to come into contact with liquids.

Silicone rubbers on the other hand are known to exhibit a high resistance and tolerance to UV radiation, excellent chemical stability, good thermal insulation characteristics, and a high tensile and tearing strength over a wide range of temperatures [29-31]. The room temperature vulcanizing types of elastomers are easy to manufacture and process in large quantities with a wide variety of surface and bulk properties to choose from. Additionally, polydimethylsiloxane(PDMS-) based polymers are still one of the most suitable elastomers for cryogenic applications due to their low glass transition temperatures [32]. By combining PCSA and RTV 655, two space-qualified materials used previously for aerospace missions [33-39], it is possible to create compound materials with unique and tunable physical and thermal properties applicable to future space exploration as well as terrestrial applications requiring expandable lightweight insulating material.

In this study, the authors fully characterized the effect of high loading and impregnation levels of micron-sized particles on the mechanical behavior of RTV 655 elastomer at two critical temperatures: room temperature and $77 \mathrm{~K}$. Microparticle impregnation levels (IL) of 25, 50, and $75 \mathrm{wt} \%$ were prepared, tested, and compared with neat RTV 655. The aerogel microparticles were created using a step-pulse pulverizing technique appropriate for creating large quantities of particles. Aerogel particles were separated mechanically into three size ranges: $d_{1}=300-425 \mu \mathrm{m}, d_{2}=180-300 \mu \mathrm{m}$, and $d_{3}=90-180 \mu \mathrm{m}$. The tensile behavior of the compound material was investigated as a function of (a) aerogel particle concentration and (b) aerogel particle size. This study shows that for low IL the aerogel particle size dominates the tensile behavior of the compound material while at high IL the behavior is dominated by the concentration of the particles rather than their physical size.

\section{Materials and Methods}

2.1. Aerogel Synthesis and Microparticle Formation. Polyurea cross-linked silica aerogels were synthesized and molded in $3 \mathrm{~mL}$ syringes as described in detail previously [32] and dried supercritically in a Quorum Technology's E3100 critical point drier. The bulk density of aerogel cylinders was determined by volumetric and gravimetric measurements and fell in the range of $0.317-0.50 \mathrm{gm} / \mathrm{cm}^{3}$. The translucency (in this case is related to degree of porosity) of each aerogel batch was evaluated by means of a Beckman DU-60 UV-Vis spectrophotometer under atmospheric conditions. A total of nine batches were synthesized for this study, each batch producing ten $3 \mathrm{~mL}$ aerogel cylinders. The density of each monolithic sample was calculated before the pulverization step.

Synthesized aerogel cylinders were next pulverized in an IKA Works Inc. grinder model A11B1S1 with an IKA A11.1 blade for a total of $60 \mathrm{~s}$ in $30 \mathrm{~s}$ intervals to avoid internal heating. The optimum pulverization time was established first on a test batch of aerogels. The aerogel powder was then passed through ASM E-11 sieves (Fisher Scientific Inc.) with mesh sizes $425 \mu \mathrm{m}, 300 \mu \mathrm{m}, 180 \mu \mathrm{m}, 90 \mu \mathrm{m}, 45 \mu \mathrm{m}$, and $20 \mu \mathrm{m}$. It was observed that over $60 \%$ of the aerogel powder mass that was created was evenly distributed in the ranges of $d_{1}=300-425 \mu \mathrm{m}, d_{2}=180-300 \mu \mathrm{m}$, and $d_{3}=90-180 \mu \mathrm{m}$ and only $20 \%$ of the total mass was distributed in the size ranges below $90 \mu \mathrm{m}$ therefore limiting the PCSA particle sizes for the study to ranges greater than $90 \mu \mathrm{m}$. Microparticles were also imaged with a scanning electron microscope periodically. The percentage of mass distribution for each pulverized batch is shown in Figure 1.

2.2. Aerogel-Impregnated RTV 655 Sample Preparation. First, a ratio of $10: 1$ RTV 655 prepolymer to cross-linker was mixed thoroughly as instructed by the manufacturer and completely outgassed in a Blue-M Precision vacuum oven. Next, equal parts of the silicone mix were poured into three separate containers and precalculated amounts of PCSA particles of three different size ranges $\left(d_{1}=300-425 \mu \mathrm{m}, d_{2}=180-300 \mu \mathrm{m}\right.$, and $\left.d_{3}=90-180 \mu \mathrm{m}\right)$ were introduced into the silicone mix such that for each particle size range samples with a $25 \%, 50 \%$, and $75 \%$ (weight percent of PCSA particles to RTV 655) were prepared. The $75 \%$ concentration was the maximum concentration that would allow full encapsulation of the microparticles and complete curing of the compound material. The neat $(0 \%$ PCSA impregnation level) and impregnated RTV 655 slurries were thoroughly mixed, outgassed, and poured into SPI-A2 polished (The Mold Polishing Company, NJ), ASTM D1708 custom-designed dog-bone molds shown in Figure 2. Great care was taken during the mixing process to avoid aerogel cluster formations. The formation of agglomerates was prevented as much as possible by microsieving the microparticles before adding them to the RTV 655 and careful and consistent mixing upon adding to the RTV 655 with mechanical agitation during the mixing phase in order to prevent (as much as possible) agglomerates from forming. The RTV $655+$ PCSA mixtures were outgassed for the final time at room temperature and then cured at $100^{\circ} \mathrm{C}$ for $1 \mathrm{hr}$. Molds were then removed from the vacuum oven and allowed to cool down prior to removal of samples from molds. Table 1 summarizes all sample groups synthesized and prepared for this study.

\subsection{Room Temperature and Low Temperature Tensile Mea-} surements. The tensile behavior of the neat and PCSAimpregnated RTV 655 samples was evaluated by means of an ESM 301 (Mark-10 Inc.) bench top tensile tester both at room temperature and at $77 \mathrm{~K}$, according to the D1708-06a ASTM standard for testing of polymers. Data acquisition and manipulation were performed using the ESM 301 manipulation software Measure. The instrument was fully calibrated following manufacturer's recommendations prior to sample testing. For low temperature measurements a custom-designed cryogenic 
TABLE 1: Summary of sample types prepared for this study.

\begin{tabular}{|c|c|c|c|c|}
\hline Sample group & Number of batches & Ingredients & PCSA diameter $=d(\mu \mathrm{m})$ & \% PCSA concentration by wt. \\
\hline \multirow{4}{*}{1} & \multirow{4}{*}{3} & RTV 655 & & $0 \%$ \\
\hline & & & & $25 \%$ \\
\hline & & RTV 655 \& PCSA & $425-300$ & $50 \%$ \\
\hline & & & & $75 \%$ \\
\hline \multirow{4}{*}{2} & \multirow{4}{*}{3} & RTV 655 & & $0 \%$ \\
\hline & & & & $25 \%$ \\
\hline & & RTV 655 \& PCSA & $300-180$ & $50 \%$ \\
\hline & & & & $75 \%$ \\
\hline \multirow{4}{*}{3} & \multirow{4}{*}{3} & RTV 655 & & $0 \%$ \\
\hline & & & & $25 \%$ \\
\hline & & RTV 655 \& PCSA & $180-90$ & $50 \%$ \\
\hline & & & & $75 \%$ \\
\hline
\end{tabular}

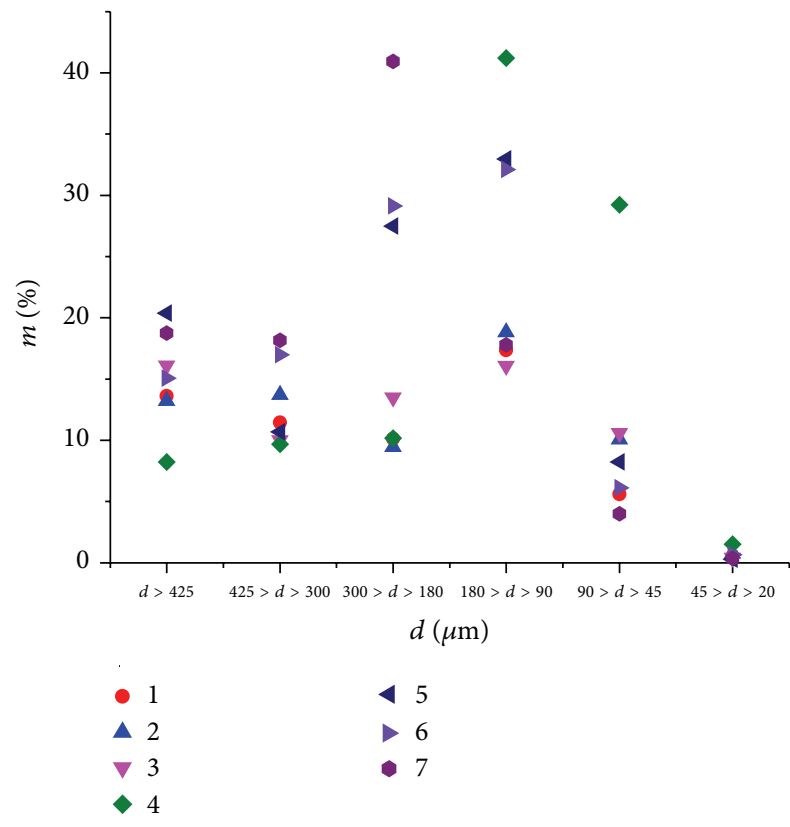

FIgURE 1: Percent mass distribution of PCSA particles for different diameter ranges for seven separate synthesis batches, after pulverization stage $(t=60 \mathrm{sec})$. The majority of PCSA microparticles created by step-pulse pulverization technique were greater than $90 \mu \mathrm{m}$ in diameter.

chamber was used. The sample under investigation was positioned between custom-designed stainless steel clamps and the assembly was positioned inside the chamber. Liquid nitrogen was then poured inside the chamber and once thermal equilibrium was accomplished the tensile test was performed.

\section{Results and Discussion}

Cross-linked silica aerogels are expected to be translucent in the visible range and heavily absorbing in the UV range. The mean UV-Vis transmittance spectra of all aerogel cylinders

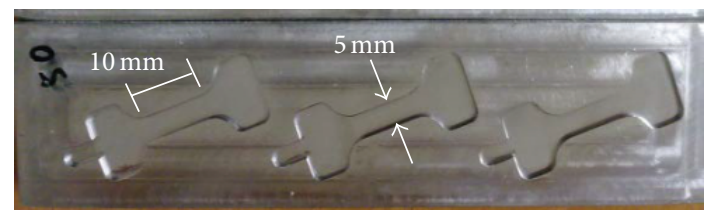

FIGURE 2: Highly polished SPI-A2 aluminum molds for curing of neat and impregnated RTV 655 samples for tensile testing. Dogbones were cut according to ASTM D1708 geometrical specifications.

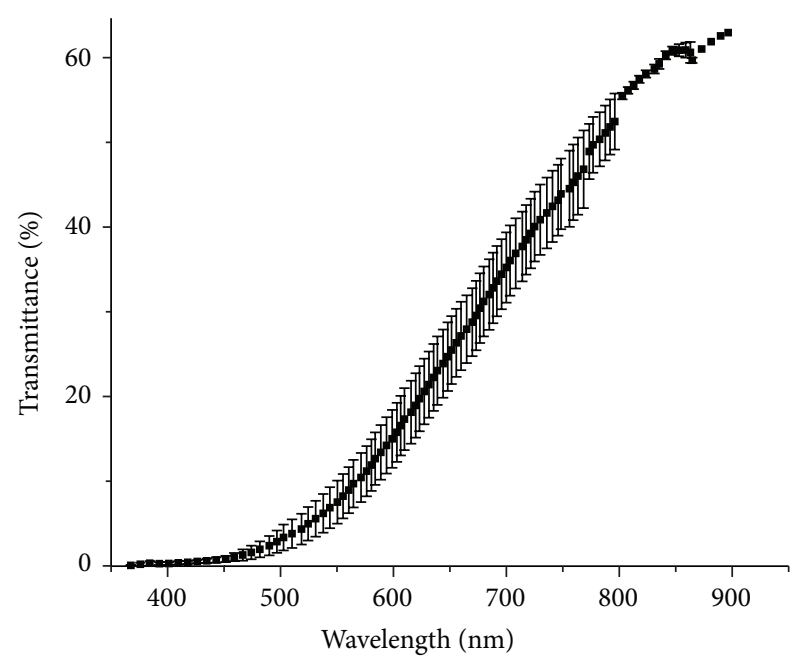

FIgURE 3: UV-Vis transmission behavior of PCSA monolithic cylinders used in this study prior to the pulverization stage. Monolithic aerogel densities of the synthesized samples fell in the range of $0.317-$ $0.5 \mathrm{gm} / \mathrm{cm}^{3}$.

used in this study are shown in Figure 3 where error bars represent the statistical standard deviation. It can be seen that transmission through each sample increases significantly as the wavelength of the incident beam increases towards the visible region, as expected. The transmittance signal is expected to be affected by the density of the aerogel sample under investigation resulting in a weaker transmitted signal 


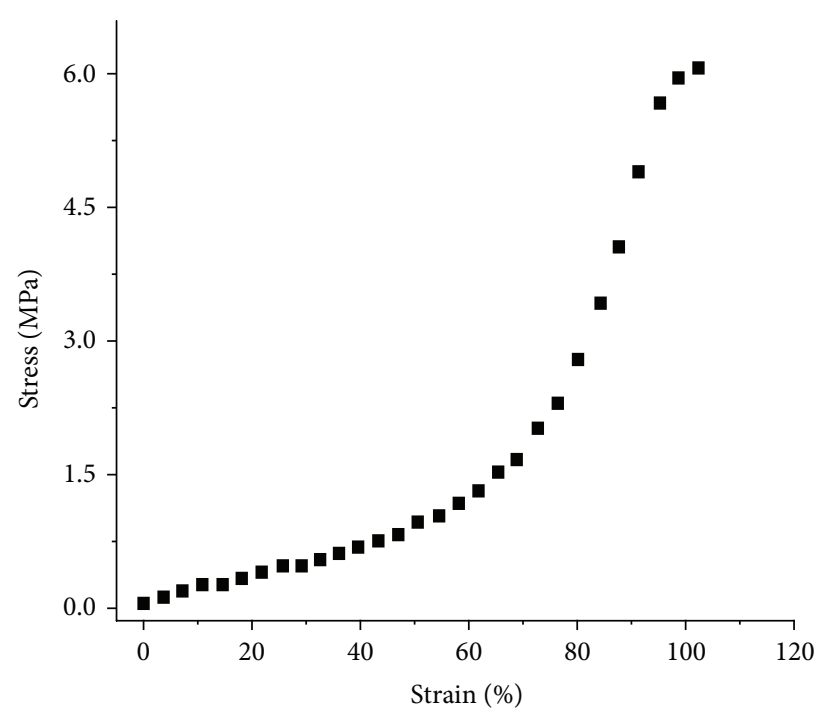

(a)

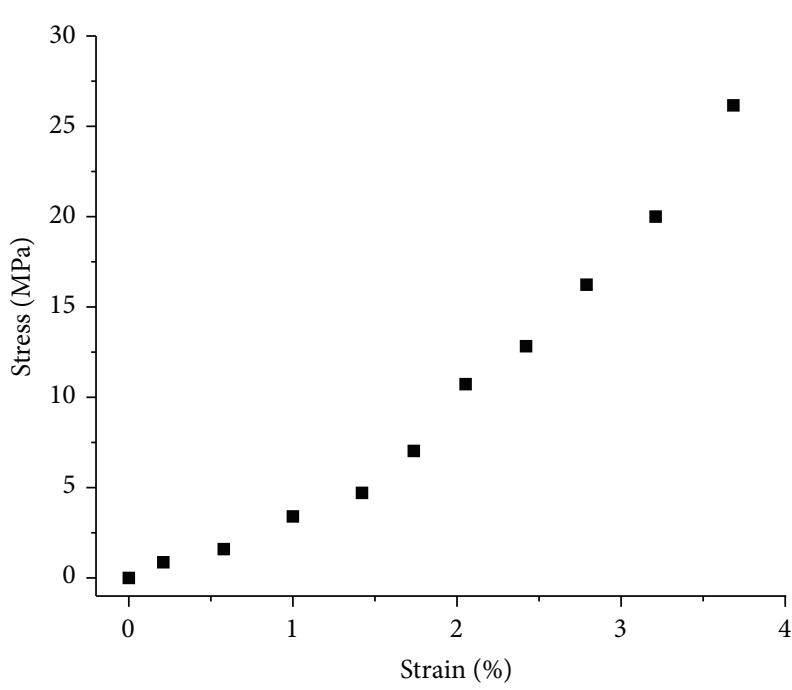

(b)

FIGURE 4: Typical tensile behavior of neat (0\% IL) RTV 655 at (a) room temperature and (b) $77 \mathrm{~K}$. The stress strain curve of RTV 655 at room temperature follows a classic elastomeric behavior. The increased strength of the polymer at $77 \mathrm{~K}$ reflects reduced mobility of the polymer chains and significant stiffening without geometrical changes such as shrinkage.

for samples with higher densities. Monolithic aerogel densities of the synthesized samples used in this study fell in the range of $0.317-0.5 \mathrm{gm} / \mathrm{cm}^{3}$ hence explaining the variations in the transmission spectra.

The typical room temperature $(300 \mathrm{k})$ and low temperature $(77 \mathrm{~K})$ tensile behavior of neat ( $0 \%$ IL) RTV 655 are shown in Figures 4(a) and 4(b), respectively, reflecting a "baseline" behavior and measurement. At room temperature the tensile behavior of 10:1 (polymer:cross-linker) RTV 655 demonstrates a classic elastomeric behavior [40, 41] as expected. The tensile behavior of neat RTV 655 at $77 \mathrm{~K}$ demonstrates a significant strengthening and stiffening of the polymer chains [32] with limited amount of elasticity and no noticeable amount of geometrical change in the form of shrinkage. The effect of PCSA microparticle incorporation on the rupture load of impregnated RTV 655 at room temperature is shown in Figure 5 for three separate sample batches measured independently and compared with the behavior of neat RTV 655 measured under similar conditions. For the largest particle sizes $\left(d_{1}=300-425 \mu \mathrm{m}\right)$ (Figure 5(a)) a drop of more than a factor of ten in rupture load is noted for the lowest IL (25\%) compared to the value for neat RTV 655 leading to a highly nonlinear profile. A less significant change in rupture load (drop by a factor 1.5) is observed when IL is increased from $25 \%$ to $75 \%$ suggesting that for the larger particle sizes the level of impregnation (loading) plays a small role in the overall mechanical strength of the compound material. In Figure 5(b) the effect of medium-sized particles $\left(d_{2}=180-300 \mu \mathrm{m}\right)$ on rupture load shows again a drop in load roughly by a factor of ten between $0 \%$ IL and $25 \%$ IL and a decrease in rupture load of 0.25 between $25 \%$ and $75 \%$ with an overall nonlinear behavior again. Finally, the effect of the smallest particle size range $\left(d_{3}=90-180 \mu \mathrm{m}\right)$ on rupture load is shown in Figure 5(c) where the decrease in rupture load between $25 \%$ and $75 \%$ is more pronounced leading to a linear material response overall. In other words, as the particle size shrinks the relationship between rupture load and IL becomes more linear and the overall tensile strength of the material increases, such that as the particle size shrinks by approximately a factor of four, the tensile strength increases by a minimum factor of two and maximum factor of five, never exceeding the rupture load of the neat RTV 655.

The effect of PCSA particle size and particle concentration on rupture load at $77 \mathrm{~K}$ is shown in Figure 6 for three separate sample batches. The strong nonlinear behavior observed at room temperature (Figures 5(a) and 5(b)) for particles size ranges $d_{1}$ and $d_{2}$ at IL $0 \%$ to $75 \%$ is repeated at $77 \mathrm{~K}$ with a linear behavior for the smallest particle size range $d_{3}$. Figures 5 and 6 suggest that, by reducing the particle size, at $25 \%$ IL the load tolerance of the compound material is comparable with the neat polymer. At IL greater than $25 \%$, however, the load bearing capability of the compound material is significantly reduced and further reduction of particle size has little effect. The rupture load variations seen from one sample batch to another are mainly attributed to particle size variations for each range and exact distribution in the polymeric matrix after the mixing and curing stage has been completed. In both cases (room temperature and $77 \mathrm{~K}$ ) the smallest particle size range $d_{3}$ leads to the highest stress to failure values, consistently for three separate batches. It is hypothesized that this can be improved by further reducing the particle diameters [42].

The effect of the microparticle size and concentration on the overall stress-elongation profile of the compound material was also investigated and compared to the behavior of the neat RTV 655 polymer. A typical room temperature response is shown in Figure 7 where at 25\% IL (Figure 7(a)) the compound material shows some degree of elasticity when 

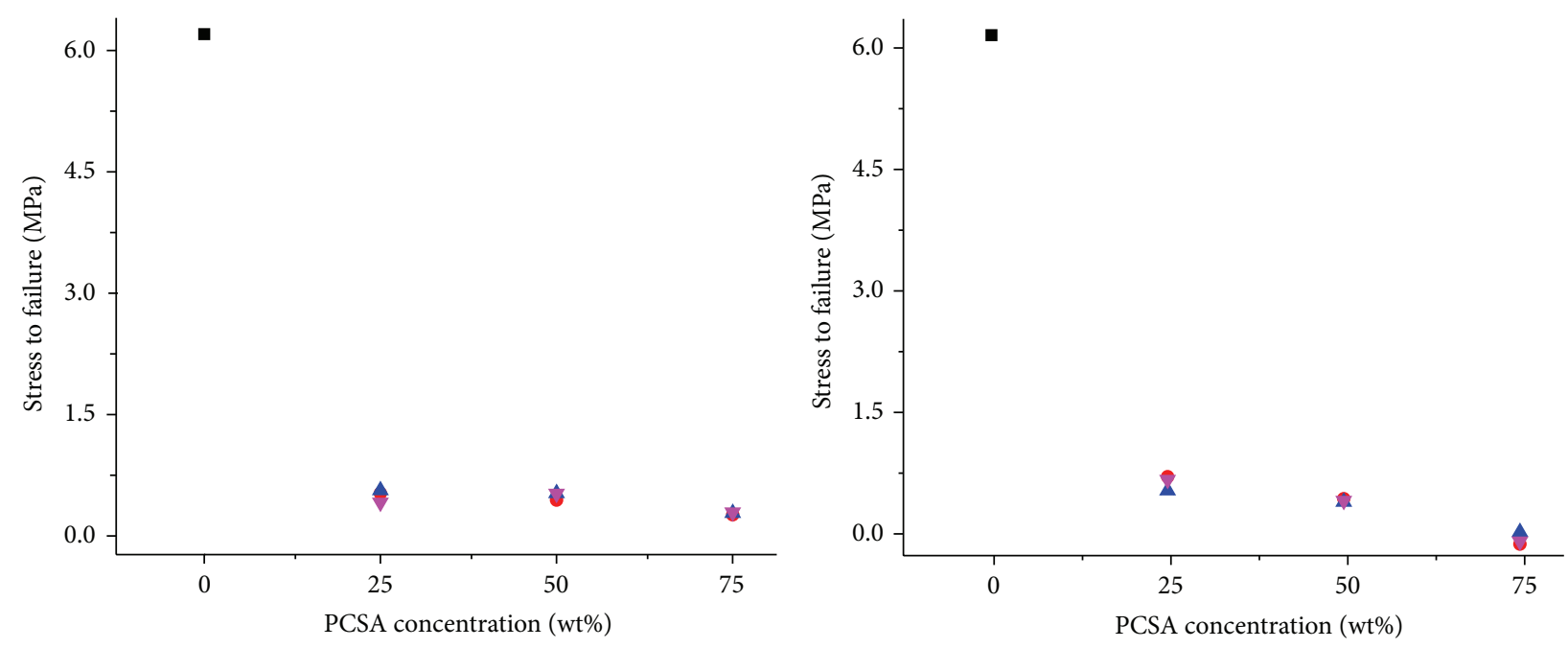

$425 \mu \mathrm{m}-300 \mu \mathrm{m}$

- Sample 1

$\checkmark$ Sample 3

$\Delta$ Sample 2

- RTV 655

$300 \mu \mathrm{m}-180 \mu \mathrm{m}$

- Sample 1

- Sample 2

(a)

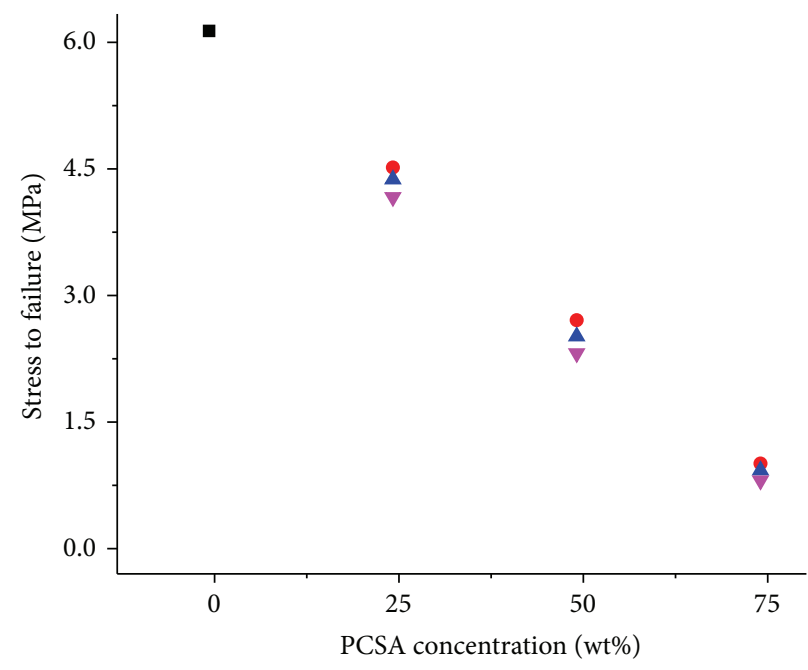

$180 \mu \mathrm{m}-90 \mu \mathrm{m}$

- Sample 1

จ Sample 3

- Sample 2

- RTV 655

(c)

Figure 5: Comparison of the rupture load of RTV 655+PCSA compound specimens at room temperature with neat (0\% IL) RTV 655 samples. Samples were impregnated with three particle size ranges: (a) $d_{1}=300-425 \mu \mathrm{m}$, (b) $d_{2}=180-300 \mu \mathrm{m}$, and (c) $d_{3}=90-180 \mu \mathrm{m}$ measured for three separate sample batches. A trend of reduction in the overall mechanical strength of compound material was observed due to incorporation of PCSA particles. However, a least amount of reduction in the yield strength of the compound sample was observed at 25 wt. (\%) impregnation with the smallest $\left(d_{3}=90-180 \mu \mathrm{m}\right)$ PCSA particles.

compared to the neat RTV 655 behavior for all microparticle diameters. As the concentration level increases to $50 \%$ (Figure 7(b)) the amount of elasticity drops significantly deviating from the elastomeric behavior and showing stiff nonelastic property with significantly lower stress tolerance. Finally, at 75\% IL (Figure 7(c)) the compound material shows stiff and brittle properties with minimum or no elasticity at all. At the $25 \%$ IL particle size did play a noticeable and distinguishable role such that some degree of plasticity was observed for each particle size range. As the IL increased, however, the effect of the particle size became insignificant compared to the effect of the IL, gradually transitioning from an elastomeric material to a stronger and tougher material (comparison of slopes). Loading levels in this study are significantly higher than those in a previously reported work [42]. 

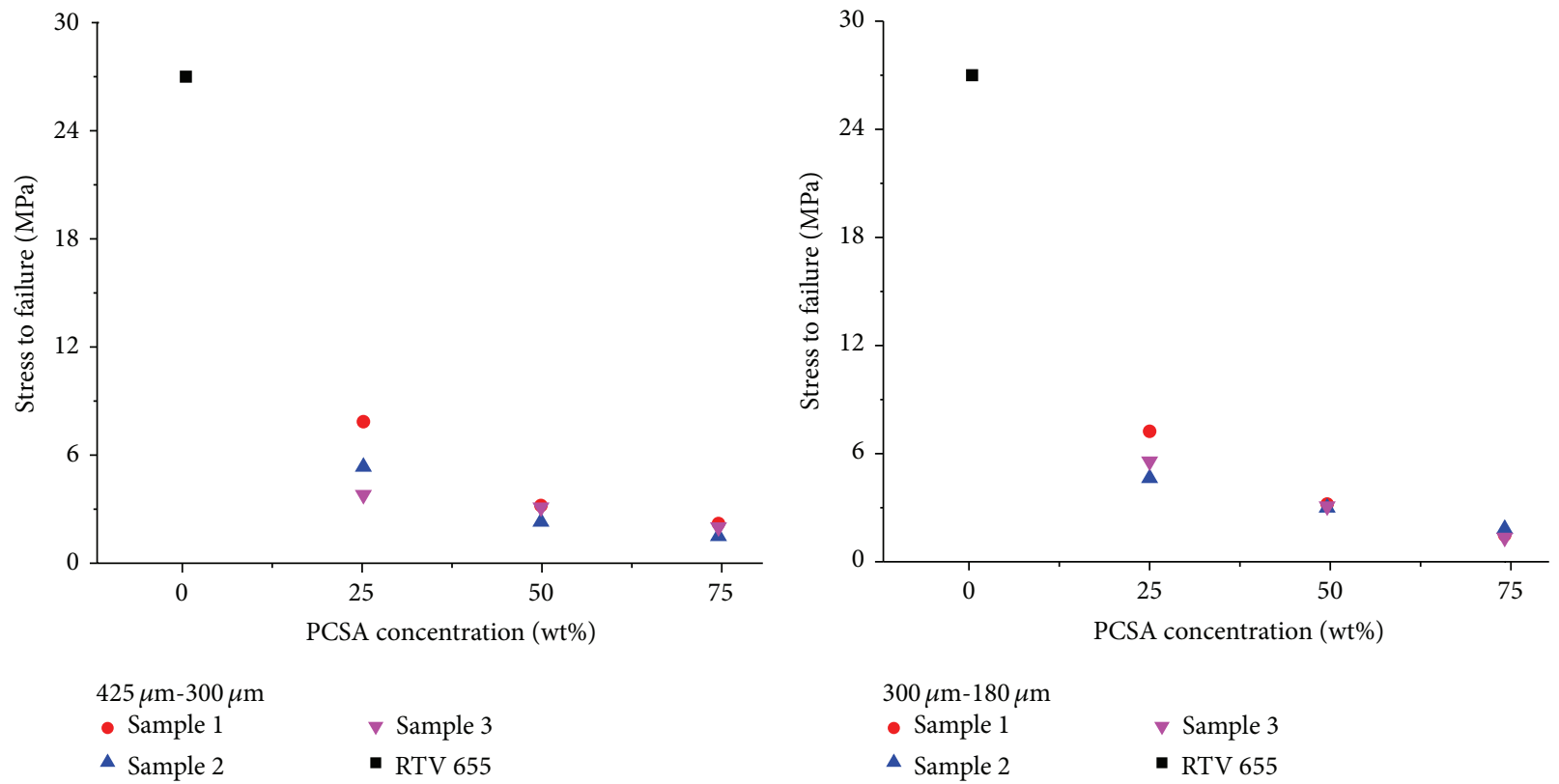

(b)

(a)

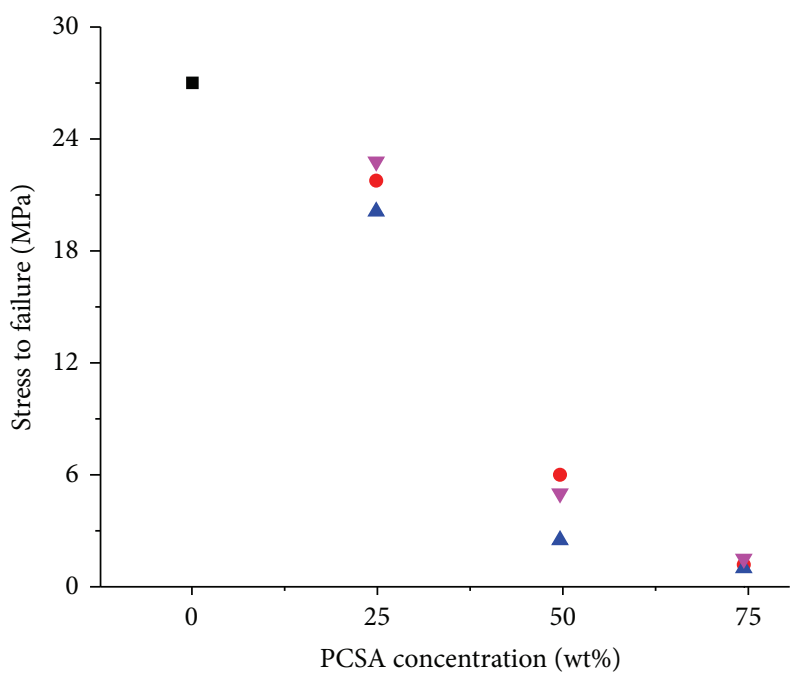

$\begin{array}{ll}180 \mu \mathrm{m}-90 \mu \mathrm{m} & \\ \text { - Sample 1 } & \nabla \text { Sample 3 } \\ \text { - Sample 2 } & \text { - RTV 655 }\end{array}$

(c)

FIGURE 6: Rupture load of RTV 655+PCSA compound specimens at $77 \mathrm{~K}$ impregnated with three particle size ranges: (a) $d_{1}=300-425 \mu \mathrm{m}$, (b) $d_{2}=180-300 \mu \mathrm{m}$, and (c) $d_{3}=90-180 \mu \mathrm{m}$ measured for three separate sample batches. A similar trend of reduction in the yield strength compared to room temperature measurements was observed. However, a considerable amount of stiffness of both neat RTV 655 and compound specimens was observed.

The stress-elongation response was also evaluated at $77 \mathrm{~K}$ for each IL level and all microparticle diameters previously discussed and is shown in Figure 8. For the 25\% IL (Figure 8(a)) the compound material has resulted in a less stiff material and overall weaker performance, rupturing at lower load values than the neat RTV 655. As the IL level increases to $50 \%$ the trend follows and finally at $75 \%$ IL the compound material demonstrates the weakest behavior.
Once again, the effect of the particle sizes studied here is less significant than the effect of the doping concentration (IL).

The overall reduction of rupture load after introducing PCSA particles into the polymer matrix is not unexpected since the hydrophobic nature of RTV 655 prevents bonding between the PCSA particles and the polymer matrix. It is hypothesized that the PCSA particles are immobilized in the polymer matrix by "physical entrapment." While interface 


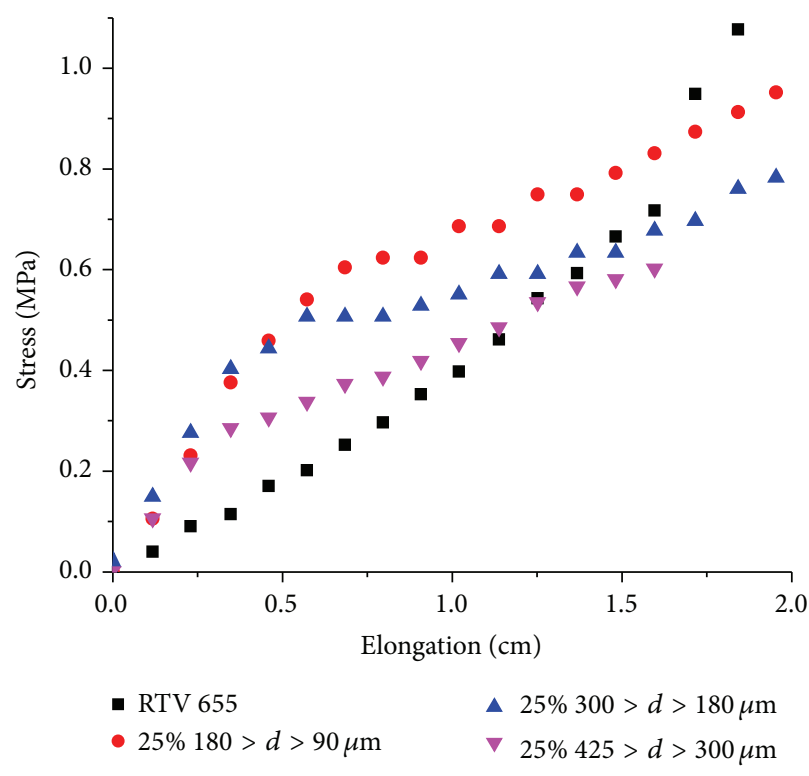

(a)

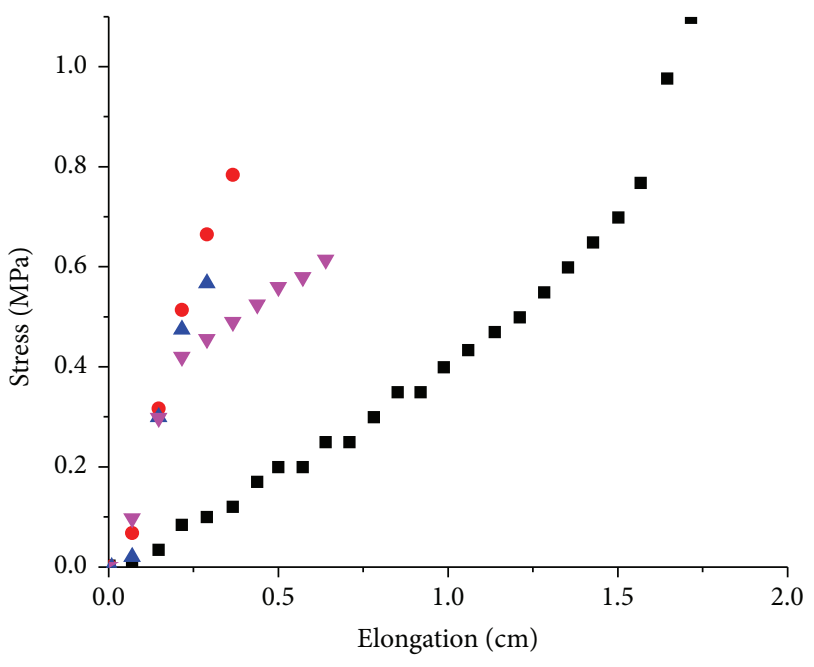

- RTV 655

- $50 \% 180>d>90 \mu \mathrm{m}$

$50 \% 300>d>180 \mu \mathrm{m}$

$\nabla 50 \% 425>d>300 \mu \mathrm{m}$

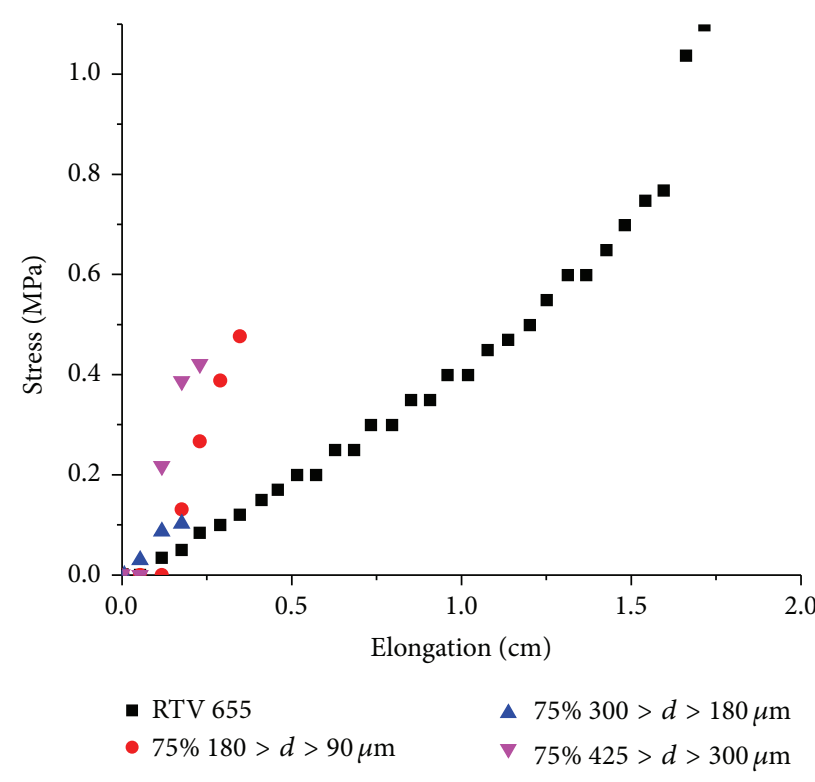

(c)

FigURE 7: Effect of PCSA particle size and concentration on the stress-elongation behavior of the compound material at room temperature. At 25\% IL (a) shows a modest deviation from elastomeric behavior in comparison to neat RTV 655. For 50\% IL (b) the compound material shows sign of a stiff material while at $75 \%$ IL (c) characteristics of a stiff and strong and more brittle material become apparent. The effect of the particle sizes seems less significant compared to the IL.

interactions cannot be fully excluded, they are highly unlikely due to (a) the hydrophobic nature of the RTV 655 and (b) observations made during tensile testing. During the tensile testing of the impregnated samples it was observed that, for the larger particles (observed with the aid of magnifiers) as the compound sample was elongated under fixed strain, the elastomeric part of the compound moved at a faster rate and was able to "slide" over the microparticles. It is expected that the same would occur at low temperatures also, but with less travel range available at those temperatures. Direct observations could not be performed at $77 \mathrm{~K}$ due to the fact that the samples are positioned in an opaque liquid nitrogen bath that is optically and physically inaccessible. This also prevented the authors from making Poisson ration measurements.

The presence of the microparticles interrupts the formation of long polymer chains and cross-linking that would have otherwise occurred at the microscopic level. Technical challenges associated with sample preparation prevented glass transition temperature measurements for impregnated samples. Scanning electron microscope (SEM) images of the pulverized cross-linked aerogels shown in Figure 9 


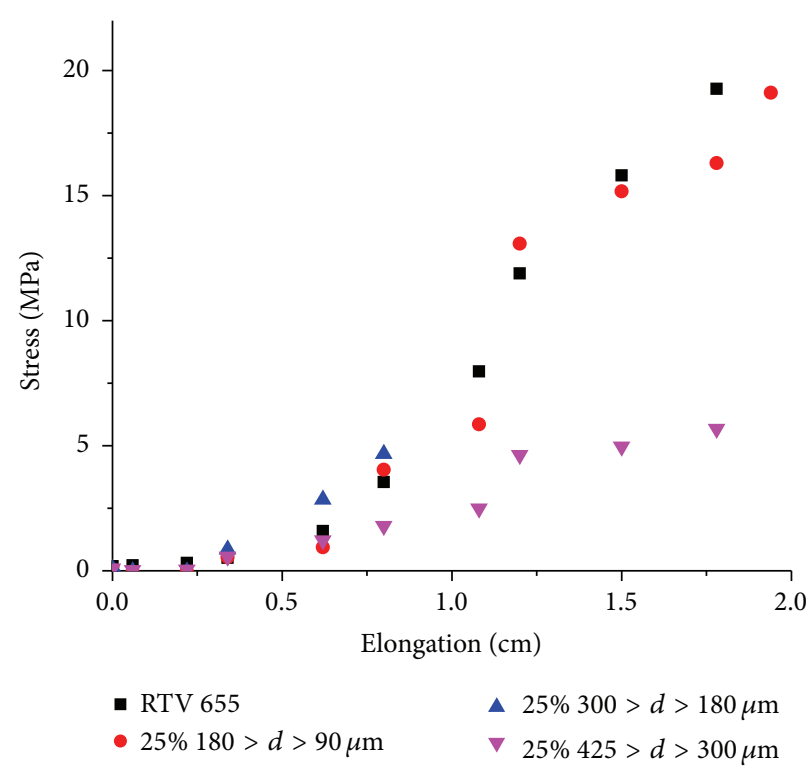

(a)

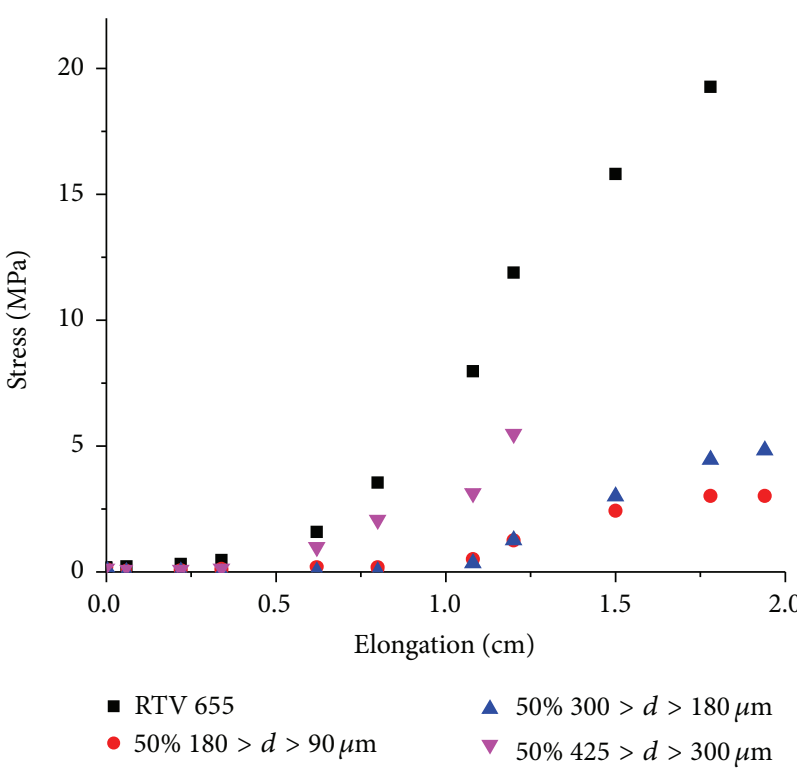

(b)

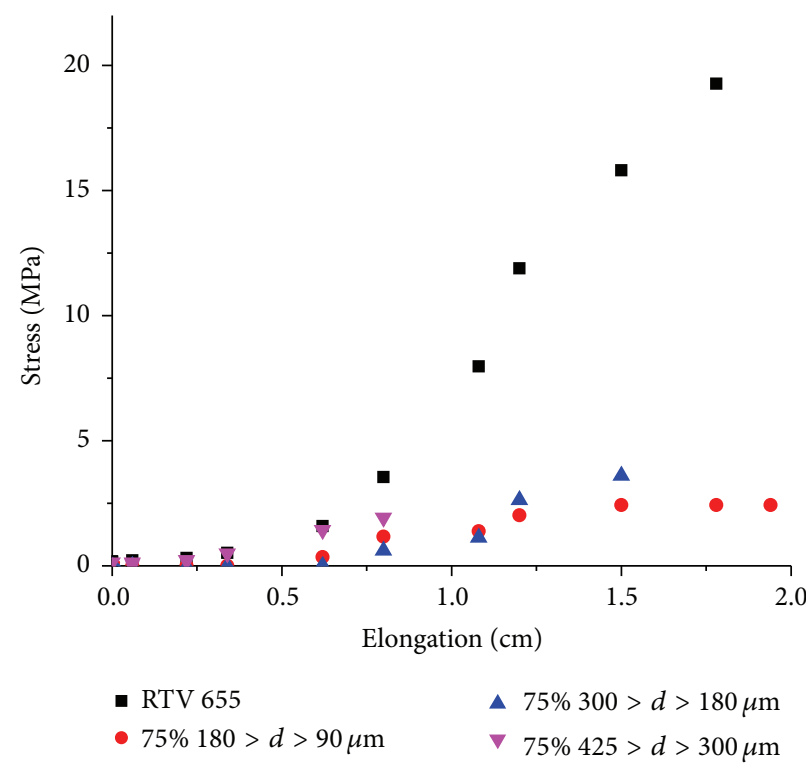

(c)

FIGURE 8: Effect of PCSA particle size and concentration on the stress-elongation behavior of the compound material at $77 \mathrm{~K}$. As IL increases from $25 \%$ (a) to $50 \%$ (b) and finally $75 \%$, (c) the compound material becomes weaker rupturing under lower load values than the neat polymer. Effect of the particle size variation seems less significant than the IL.

demonstrate a highly irregular geometry which is the result of the step-pulse pulverizing technique. The geometrical irregularity observed in the microparticles formed affects the magnitude and profile of stress concentrations at the microscopic scale and hence affects the macroscopic mechanical behavior that is measured for each sample. While it is possible to create large quantities of microparticles of varying diameters using this technique, the irregular geometry is thought to contribute significantly towards lowering the rupture load values.

\section{Summary and Conclusion}

The limitation performance of an aerogel-impregnated RTV 655 elastomer was evaluated for two critical temperatures. Aerogel microparticles were created by means of a step-pulse pulverizing technique that was easy to process and suitable for the formation of large volumes of microparticles. This method however provided little control over the particle geometry and more specifically surface morphology. The majority of microparticles created using this technique had 


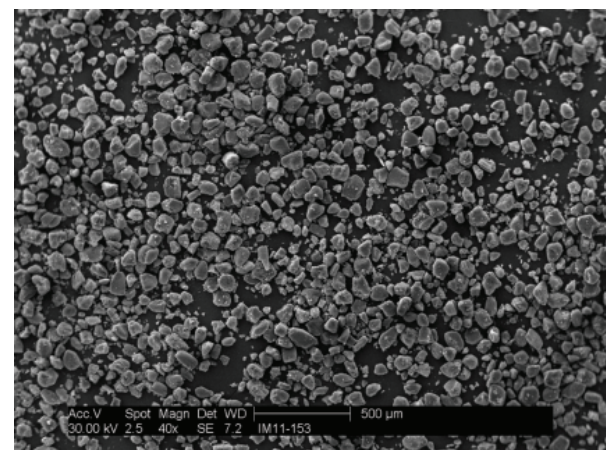

FIGURE 9: SEM image of pulverized cross-linked silica aerogels showing nonuniform geometries created by using the step-pulse pulverizing technique.

diameters greater than $90 \mu \mathrm{m}$, setting the lower limit of the microparticle size distributions used in this study. It was discovered that the maximum impregnation and loading level that resulted in complete curing and encapsulation was discovered to be $75 \mathrm{wt} \%$.

The effect of size and concentration of polyurea crosslinked silica aerogel microparticles on the tensile behavior of the elastomer RTV 655 was fully characterized at two critical temperatures of room temperature and $77 \mathrm{~K}$. As the concentration of PCSA microparticles increased from 0 to $75 \mathrm{wt} \%$ the tensile behavior of the compound material transitioned from an elastic behavior to a stiff and tough material. For IL of 25 and $50 \mathrm{wt} \%$ the effect of microparticle diameter on overall material response was identifiable. At IL $75 \mathrm{wt} \%$ however the concentration level dominated the material behavior with little influence from the particle diameter variations. Overall, the size of the PCSA particles impacted the rupture load values the most while the concentration of the PCSA particles in the RTV 655 matrix dominated the stress-elongation behavior. It is expected that by further reducing the particle sizes significant increase in the rupture load values will be seen.

\section{Conflict of Interests}

The authors declare that there is no conflict of interests regarding the publication of this paper.

\section{Acknowledgments}

The authors would like to acknowledge the financial support from NASA TN EPSCOR NNX10AQ71A. The authors would also like to thank John Daffron from the Department of Physics Instrument Shop at the University of Memphis as well as Robert Hewitt at the University of Memphis for technical support.

\section{References}

[1] F. Sabri, J. A. Cole, M. C. Scarbrough, and N. Leventis, "Investigation of polyurea-crosslinked silica aerogels as a neuronal scaffold: a pilot study," PLoS ONE, vol. 7, no. 3, Article ID e33242, 2012.
[2] T. Mehling, I. Smirnova, U. Guenther, and R. H. H. Neubert, "Polysaccharide-based aerogels as drug carriers," Journal of Non-Crystalline Solids, vol. 355, no. 50-51, pp. 2472-2479, 2009.

[3] Y. K. Li, M. J. Chou, T.-Y. Wu, T.-R. Jinn, and Y. W. ChenYang, "A novel method for preparing a protein-encapsulated bioaerogel: using a red fluorescent protein as a model," Acta Biomaterialia, vol. 4, no. 3, pp. 725-732, 2008.

[4] M. D. Frogley, D. Ravich, and H. D. Wagner, "Mechanical properties of carbon nanoparticle-reinforced elastomers," Composites Science and Technology, vol. 63, no. 11, pp. 1647-1654, 2003.

[5] S.-Y. Fu and B. Lauke, "Fracture resistance of unfilled and calcite-particle-filled ABS composites reinforced by short glass fibers (SGF) under impact load," Composites Part A: Applied Science and Manufacturing, vol. 29, no. 5-6, pp. 631-641, 1998.

[6] A. C. Moloney, H. H. Kausch, T. Kaiser, and H. R. Beer, "Parameters determining the strength and toughness of particulate filled epoxide resins," Journal of Materials Science, vol. 22, no. 2, pp. 381-393, 1987.

[7] A. J. Kinloch and R. J. Young, "Fracture behavior of polymers," British Polymer Journal, vol. 16, no. 2, p. 114, 1984.

[8] M. E. J. Dekkers and D. Heikens, "The effect of interfacial adhesion on the tensile behavior of polystyrene-glass-bead composites," Journal of Applied Polymer Science, vol. 28, no. 12, pp. 3809-3815, 1983.

[9] S.-Y. Fu and B. Lauke, "Characterization of tensile behaviour of hybrid short glass fibre/calcite particle/ABS composites," Composites A: Applied Science and Manufacturing, vol. 29, no. 5-6, pp. 575-583, 1998.

[10] K. C. Radford, "The mechanical properties of an epoxy resin with a second phase dispersion," Journal of Materials Science, vol. 6, no. 10, pp. 1286-1291, 1971.

[11] Y. Nakamura, M. Yamaguchi, M. Okubo, and T. Matsumoto, "Effects of particle size on mechanical and impact properties of epoxy resin filled with spherical silica," Journal of Applied Polymer Science, vol. 45, no. 7, pp. 1281-1289, 1992.

[12] L. Nicolais and L. Nicodemo, "Effect of particles shape on tensile properties of glassy thermoplastic composites," International Journal of Polymeric Materials, vol. 3, no. 3, pp. 229-243, 1974.

[13] T. K. Jayasree and P. Predeep, "Effect of fillers on mechanical properties of dynamically crosslinked styrene butadiene rubber/high density polyethylene blends," Journal of Elastomers and Plastics, vol. 40, no. 2, pp. 127-146, 2008.

[14] K. W. Bills Jr., K. H. Sweeny, and F. S. Salcedo, "The tensile properties of highly filled polymers. Effect of filler concentrations," Journal of Applied Polymer Science, vol. 4, no. 12, pp. 259-268, 1960.

[15] C.-H. Hsueh, "Effects of aspect ratios of ellipsoidal inclusions on elastic stress transfer of ceramic composites," Journal of the American Ceramic Society, vol. 72, no. 2, pp. 344-347, 1989.

[16] R. J. Young and P. W. R. Beaumont, "Failure of brittle polymers by slow crack growth-Part 3 Effect of composition upon the fracture of silica particle-filled epoxy resin composites," Journal of Materials Science, vol. 12, no. 4, pp. 684-692, 1977.

[17] B. Pukanszky and G. Voros, "Mechanism of interfacial interactions in particulate filled composites," Composite Interfaces, vol. 1, no. 5, pp. 411-427, 1993.

[18] Y. Ou, F. Yang, and Z.-Z. Yu, "A new conception on the toughness of nylon 6/silica nanocomposite prepared via in situ polymerization," Journal of Polymer Science, Part B: Polymer Physics, vol. 36, no. 5, pp. 789-795, 1998. 
[19] Z. K. Zhu, Y. Yang, J. Yin, and Z. N. Qim, "Preparation and properties of organosoluble polyimide/silica hybrid materials by sol-gel process," Journal of Applied Polymer Science, vol. 73, no. 14, pp. 2977-2984, 1999.

[20] E. Reynaud, T. Jouen, C. Gauthier, G. Vigier, and J. Varlet, "Nanofillers in polymeric matrix: a study on silica reinforced PA6," Polymer, vol. 42, no. 21, pp. 8759-8768, 2001.

[21] B. E. Yoldas, M. J. Annen, and J. Bostaph, "Chemical engineering of aerogel morphology formed under nonsupercritical conditions for thermal insulation," Chemistry of Materials, vol. 12, no. 8, pp. 2475-2484, 2000.

[22] B. Wolff, G. Seybold, and F. E. Krueckau, “Thermal insulators having density 0.1 to $0.4 \mathrm{~g} / \mathrm{cm}^{3}$, and their manufacture BASFG," European Patent Applications 0340707, 2010.

[23] F. Sabri, J. Marchetta, and K. M. Smith, “Thermal conductivity studies of a polyurea cross-linked silica aerogel-RTV 655 compound for cryogenic propellant tank applications in space," Acta Astronautica, vol. 91, pp. 173-179, 2013.

[24] B. E. Scholtens, J. E. Fesmire, J. P. Sass, S. D. Augustynowicz, and K. W. Heckle, "Cryogenic thermal performance testing of bulkfill and aerogel insulation materials," in Proceedings of the AIP Conference, pp. 152-159, Chattanooga, Tenn, USA, 2008.

[25] M. K. Williams, T. M. Smith, and J. E. Fesmire, "Aerogel/polymer composite materials," US Patent no. US7790787, 2010 .

[26] K. S. Novak, C. J. Phillips, G. C. Burir, E. T. Sunada, and M. T. Pauken, "Development of a thermal control architecture for the Mars Exploration Rovers," in Proceedings of the AIP Conference, pp. 194-205, 2003.

[27] A. Katti, N. Shimpi, S. Roy et al., "Chemical, physical, and mechanical characterization of isocyanate cross-linked aminemodified silica aerogels," Chemistry of Materials, vol. 18, no. 2, pp. 285-296, 2006.

[28] H. Luo, G. Churu, E. F. Fabrizio et al., "Synthesis and characterization of the physical, chemical and mechanical properties of isocyanate-crosslinked vanadia aerogels," Journal of Sol-Gel Science and Technology, vol. 48, no. 1-2, pp. 113-134, 2008.

[29] Y. Jia, S. Sun, L. Liu, S. Xue, and G. Zhao, "Investigation of computer-aided engineering of silicone rubber vulcanizing (I) - vulcanization degree calculation based on temperature field analysis," Polymer, vol. 44, no. 1, pp. 319-326, 2002.

[30] Q. G. Gu and Q. L. Zhou, "Preparation of high strength and optically transparent silicone rubber," European Polymer Journal, vol. 34, no. 11, pp. 1727-1733, 1998.

[31] M. Patel, A. R. Skinner, and R. S. Maxwell, "Sensitivity of condensation cured polysiloxane rubbers to sealed and opento air thermal ageing regimes," Polymer Testing, vol. 24, no. 5, pp. 663-668, 2005.

[32] D. A. Wigley, Mechanical Properties of Materials at Low Temperatures, Plenum Press, New York, NY, USA, 1971.

[33] M. A. B. Meador, S. L. Vivod, L. McCorkle et al., "Reinforcing polymer cross-linked aerogels with carbon nanofibers," Journal of Materials Chemistry, vol. 18, no. 16, pp. 1843-1852, 2008.

[34] S. Mulik, C. Sotiriou-Leventis, and N. Leventis, "Macroporous electrically conducting carbon networks by pyrolysis of isocyanate-cross-linked resorcinol-formaldehyde aerogels," Chemistry of Materials, vol. 20, no. 22, pp. 6985-6997, 2008.

[35] M. A. B. Meador, L. A. Capadona, L. McCorkle, D. S. Papadopoulos, and N. Leventis, "Structure-property relationships in porous 3D nanostructures as a function of preparation conditions: isocyanate cross-linked silica aerogels," Chemistry of Materials, vol. 19, no. 9, pp. 2247-2260, 2007.
[36] F. Sabri, T. Werhner, J. Hoskins et al., “Thin film surface treatments for lowering dust adhesion on Mars Rover calibration targets," Advances in Space Research, vol. 41, no. 1, pp. 118-128, 2008.

[37] J. K. Lee, G. L. Gould, and W. Rhine, "Polyurea based aerogel for a high performance thermal insulation material," Journal of Sol-Gel Science and Technology, vol. 49, no. 2, pp. 209-220, 2009.

[38] F. Sabri, N. Leventis, J. Hoskins et al., "Spectroscopic evaluation of polyurea crosslinked aerogels, as a substitute for RTV-based chromatic calibration targets for spacecraft," Advances in Space Research, vol. 47, no. 3, pp. 419-427, 2011.

[39] J. L. Goudie and T. P. Collins, "Development and evaluation of an improved RTV coating for outdoor insulation," in Proceedings of the IEEE International Symposium on Electrical Insulation, pp. 475-479, Indianapolis, Ind, USA, September 2004.

[40] W. D. Callister Jr. and D. G. Rethwisch, Material Science and Engineering: An Introduction, John Wiley \& Sons, Hoboken, NJ, USA, 8th edition, 2010.

[41] F. Schneider, T. Fellner, J. Wilde, and U. Wallrabe, "Mechanical properties of silicones for MEMS," Journal of Micromechanics and Microengineering, vol. 18, no. 6, Article ID 065008, 2008.

[42] Z. Wang, J. Liu, S. Wu, W. Wang, and L. Zhang, "Novel percolation phenomena and mechanism of strengthening elastomers by nanofillers," Physical Chemistry, Chemical Physics, vol. 12, no. 12, pp. 3014-3030, 2010. 

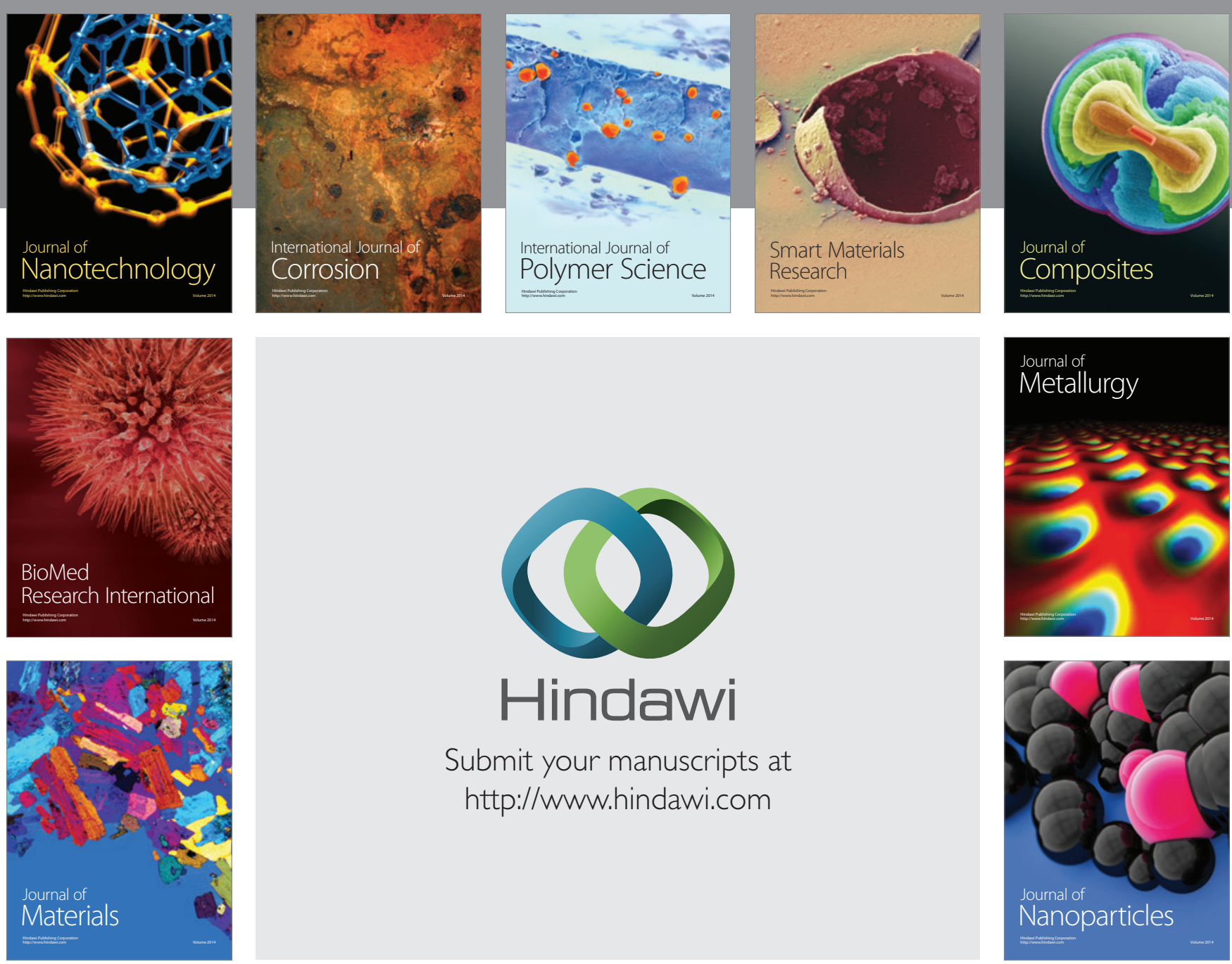

Submit your manuscripts at http://www.hindawi.com
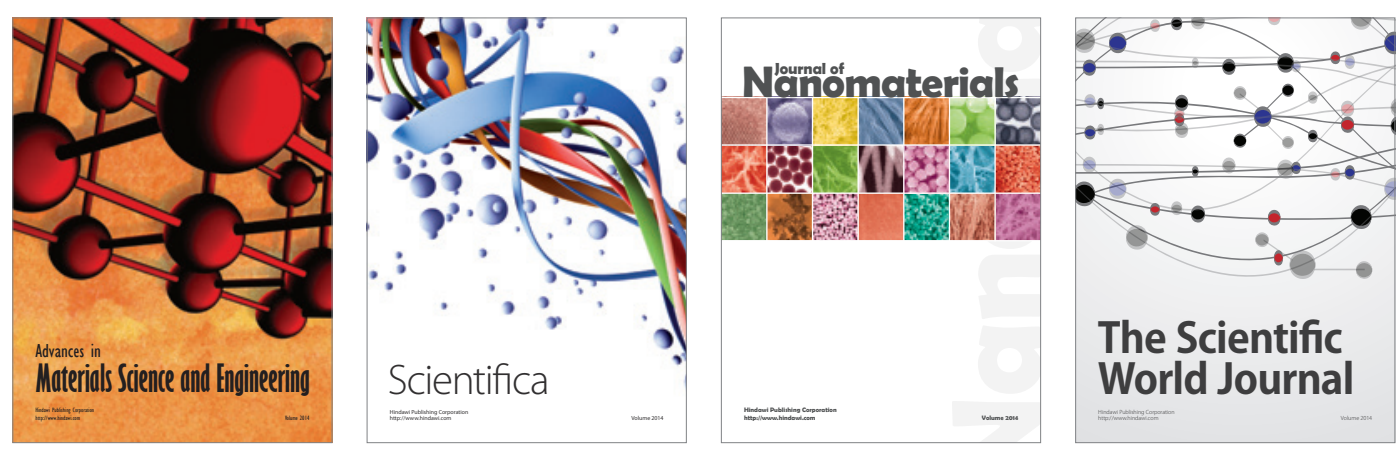

\section{The Scientific World Journal}
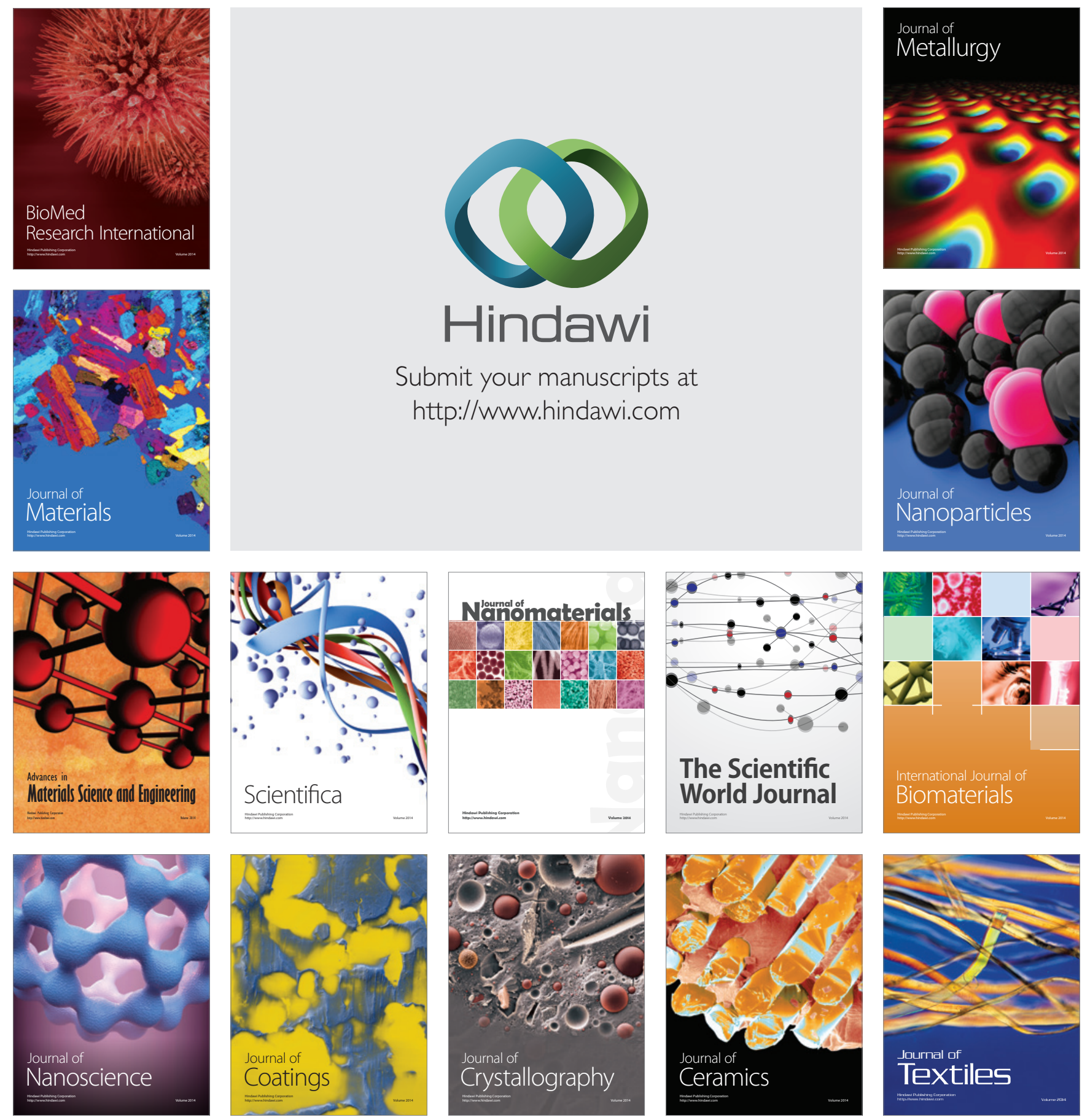